\title{
APRESENTAÇ̃̃o
}

\section{DOSSIÊ \\ ORGANISMOS MULTILATERAIS E POLÍTICAS PÚBLICAS NO CENÁRIO DA EDUCAÇÃO BÁSICA E SUPERIOR: DIRETRIZES, DESAFIOS E PRÁTICAS}

Para apresentar o debate acerca da relevância da temática central do dossiê Organismos multilaterais e políticas públicas no cenário da educação básica e superior: diretrizes, desafios e práticas, assumimos o pressuposto da necessária compreensão de que as políticas públicas educacionais globais são decorrentes de múltiplas realidades, diretrizes e processos de gestão que são prioridade em nível mundial e que interferem na articulação e no funcionamento dos sistemas educacionais em nível local.

Nessa perspectiva, os organismos multilaterais constituem-se entidades criadas pelas principais nações do mundo e respectivos blocos econômicos, que estão inseridos na conjuntura das relações internacionais, na lógica da interlocução e desenvolvimento global e local voltado para as múltiplas áreas da atividade humana. O organismo multilateral ou organização internacional, como entidade que tem concepção e abrangência supranacional composta por vários países, tem priorizado apresentar uma visão diagnóstica e diretrizes orientadoras às políticas públicas, além de promover acordos de cooperação entre os países-membros, considerando a adoção conjunta de aspectos normatizadores de comportamento e desenvolvimento comercial, cultural, educacional, oferta e atendimento de saúde, estabelecimento de redes de proteção, entre outros.

Desde os anos 1990, organismos multilaterais como a Organização das Nações Unidas (ONU), a Organização das Nações Unidas para educação, ciência e cultura (Unesco), o Instituto Internacional da Unesco para a Educação Superior na América Latina e no Caribe (Iesalc), a Organização para a Cooperação e o Desenvolvimento Econômico (OECD), a Organização Mundial da Saúde (OMS), o Banco Internacional para Reconstrução e Desenvolvimento (BIRD), também conhecido como Banco Mundial, o Fundo Monetário Internacional (FMI), a Organização Mundial 
do Comércio (OMC), a União Europeia e a Organização dos Estados Ibero Americanos (OEI) aumentaram seu escopo de prioridades e atividades, justificando a qualidade de vida da população mundial e introduzindo e disseminando novas ideologias e desafios em âmbito global e, consequentemente, local. Essas organizações internacionais têm se configurado de maneira complexa nas suas relações com a comunidade mundial, interferindo diretamente nas políticas internacionais e domésticas, estabelecendo e [re]formatando redes e estruturas societais em suas diversas áreas e dimensões, entre elas a área da educação. Essa realidade pode ser verificada a exemplo das inserções e participações de diferentes países em reuniões e foros globais ou regionais, na pactuação de tratados de cooperação, na realização de fóruns e conferências, na proposição de agendas desenvolvimentistas e solidárias a várias causas sociais, entre outras dinâmicas e estratégias de congregação de interesses em defesa da legitimação do diálogo permanente entre as nações, em suas relações internacionais e estabelecendo prioridades entre os membros dos diversos grupos de países.

Mais pontualmente, no que diz respeito às políticas educacionais, temse vislumbrado que tais organismos estão envolvidos em: fomento e produção de plataformas de políticas de ensino e gestão educacional; produção de relatórios diagnósticos e analíticos relacionados a diferentes nações e áreas sociais; revisões temáticas entre os países contendo a proposição e disseminação de políticas, orientações e metas com base na produção de diagnósticos; implementação e coordenação de políticas entre os países-membros; construção de dados que repercutem em tendências e diretrizes educacionais, entre outros aspectos.

$\mathrm{Na}$ lógica do mundo globalizado, os pesquisadores de distintas áreas têm se posicionado acerca das iniciativas, das orientações e interferências dos organismos multilaterais na relação global norte e global sul, tensionando a perspectiva de que existem países clientes e passíveis de dominação e dependência neocolonial que se reproduz historicamente, o que, para muitos, nada mais é do que a causa e a consequência da dependência clientelista, tornando-se um limite local o processo de decisão global dos países desenvolvidos.

Assim, este dossiê constitui-se num arcabouço de reflexões e tensionamentos acerca da temática em evidência e considera o fenômeno da globalização e suas conexões com os organismos multilaterais como produtores de sentido e orientações internacionais para as políticas públicas educacionais, na perspectiva de que tais políticas ultrapassam fronteiras e constroem relações sistêmicas e [re]produtivas 
na dinâmica das instituições educacionais nos diferentes continentes e países. São complexas e multidimensionais as relações macro e microeducacionais, tendo em vista o crescente fenômeno da internacionalização da educação, bem como as interveniências de tais organismos em seus princípios e prioridades para o desenvolvimento mundial. Nesse sentido, as interferências e conexões transnacionais repercutem na definição de metas e estratégias alocadas nos marcos regulatórios e nos planos e programas educacionais decorrentes, tornando-se força premente e [re] produtiva de transformações sociais em larga e pequena escala.

Considerando a conjuntura deste dossiê composta por nove artigos e duas resenhas, e tendo como referência analítica a inter-relação dos organismos multilaterais com a produção de políticas públicas mundiais, bem como seus efeitos em diversificados cenários educacionais nacionais, em especial o Brasil, em interlocução com o contexto Latino-Americano e Ibero-Americano, destacamos a importância dos resultados e análises subjacentes a pesquisas científicas voltadas para fatores e fenômenos que têm abarcado e contribuído para a constituição de novos lócus de organização e funcionamento da Educação Básica e Superior, considerando que com os três artigos decorrentes de produções de autores internacionais (Estados Unidos, Uruguai e Espanha,) e os seis artigos de autores brasileiros de Instituições de Ensino Superior das regiões Sul e Sudeste, encontramos a possibilidade de reflexionar de maneira crítica acerca da função social da Educação Básica e Superior para a formação do cidadão global, bem como da formação, atuação e desenvolvimento dos profissionais da educação no cenário multifacetado de políticas públicas educacionais e respectivas metas que rompem com os limites das fronteiras nacionais e se entrecruzam em uma esfera mundial desenvolvimentista e repleta de dualidades.

No primeiro texto, Academic capitalism and the entrepreneurial university, das autoras Patricia Somer, Cory Davis, Jessic Fry, Lisa Jasinski e Elida Lee, encontram-se discussões acerca do capitalismo acadêmico e suas relações com a universidade empresarial. Tal perspectiva considera os professores como produtores de capital e os estudantes como consumidores. $\mathrm{O}$ artigo também aborda o capitalismo acadêmico na América Latina e no Brasil.

Em La internacionalización y la interlocución entre la educación básica y superior: el problema de la formación docente, um manuscrito produzido por Patricia Viera-Duarte, estão presentes as interlocuções entre demandas e desafios da Educação Básica no cenário latino-americano, com as inovações da formação de professores 
instalados no Ensino Superior cada vez mais internacionalizado. A autora parte de uma série de estudos qualitativos no contexto da hermenêutica, que conclui com algumas recomendações para (re)articular os diálogos regionais, nacionais e subnacionais nos seus diversos níveis.

Na terceira produção, A educação para a cidadania mundial como aposta de construção de um novo paradigma educativo, os autores Luis Miguel Lázaro Lorente, Victoria Martín de la Rosa e Cristina Pulido Monte reflexionam acerca da cidadania global, considerando a evidência da sua permanência como prioridade na agenda educativa mundial, tanto para os países desenvolvidos quanto para os em desenvolvimento. Os autores sinalizam que a Educação para a Cidadania Mundial tem cobrado ao longo dos últimos anos um claro protagonismo na reflexão e nas práticas educativas, tanto das Organizações Não Governamentais quanto dos docentes mais comprometidos com um pensar e uma prática pedagógica alternativa em suas aulas. Sua inclusão preeminente na agenda global como raiz de sua definição prioritária para o marco da Global Education First Initiative (GEFI), que impulsiona as Nações Unidas, pode tornar muito mais visível a necessidade de aprofundar o seu desenvolvimento.

Marilene Gabriel Dalla Corte, Rosane Carneiro Sarturi e Janilse Fernandes Nunes, no manuscrito Políticas de formação de professores no Brasil: desdobramentos e interlocução com diretrizes dos organismos internacionais, discutem a respeito das políticas de formação dos professores no Brasil a partir da década de 1990, seus desdobramentos e as recomendações de organismos internacionais. As autoras examinam as políticas e programas no campo da formação docente, na perspectiva de aproximar as principais diretrizes mundiais relacionadas às prioridades de qualificação dos profissionais da educação e destacam que as reformas educacionais brasileiras estão intimamente articuladas com as recomendações/orientações dos organismos internacionais que atuam como mecanismos para atender às demandas de processos produtivos e performativos oriundos da lógica global.

No texto Internacionalização do Currículo: produção em organismos multilaterais, Marília Costa Morossini reflexiona sobre a expansão da internacionalização da Educação Superior no contexto da globalização e da Sociedade do Conhecimento, apontando que organismos multilaterais capitaneados pela OCDE passaram a propor outras formas para a internacionalização, como a do currículo (IoC). É apontada a complexidade da concepção que se estende desde a formação profissional para o mercado globalizado até a formação do cidadão global. 
O manuscrito Políticas públicas para a educação infantil no Brasil: desafios à consolidação do direito no contexto emergente da nova filantropia, produzido por Maria Luiza Flores e Vera Maria Vidal Peroni, analisa avanços e tensões no campo das políticas públicas educacionais no sentido da efetivação do direito à educação infantil no Brasil. As autoras sinalizam que a avaliação da trajetória dessa etapa educacional, de 1996 até os dias atuais, evidencia a consolidação de um conjunto normativo global e regulador que não garantiu acesso e qualidade para todos. Argumentam que a concepção de educação infantil presente nos dispositivos legais ainda não se materializou plenamente em políticas públicas garantidoras desse direito educacional, estando fortemente ameaçada por modelos privatistas caracterizados como uma nova filantropia.

No artigo Efeitos das politicas internacionais e a emergência do PNAICPacto no Brasil, as autoras Leandra Boer Possa e Patrícia Luciene de Albuquerque Bragamonte trabalham com a análise de discurso foucaultiano como meio de produzir argumentações a partir do procedimento de apropriação dos enunciados utilizados no PNAIC, os quais são tomados em suas condições de funcionamento. Para tanto, apresentam, a partir da analítica síntese argumentativa, o PNAIC como um programa-efeito das políticas neoliberais em educação movimentadas para desenvolvimento econômico e social do neoliberalismo projetado pelos organismos internacionais na educação.

Maria de Lourdes Pinto Almeida e Fernando Rodrigo Dall Igna, no manuscrito Grupos de investigação em educação superior: por onde anda a produção do conhecimento cientifico?, apresentam o perfil dos grupos de pesquisa em Educação Superior cadastrados no Diretório de Pesquisa do Conselho Nacional de Desenvolvimento Científico e Tecnológico (CNPq) em universidades públicas da região Sul do Brasil. As discussões contribuem para identificar os eixos temáticos que caminham à produção do conhecimento científico via pesquisa na Educação Superior no Brasil, destacando como consequência a efetiva e tão discutida ideia de (re)produtivismo acadêmico em nível mundial e suas repercussões no Brasil.

A pedagogia do herói sob as performances das políticas públicas contemporâneas, texto produzido por Eli Terezinha Henn Fabris, aborda elementos da racionalidade neoliberal no contexto da educação global e local, produzindo regras para o processo de avaliação e performances cada vez mais altas para o desempenho docente e para as instituições de formação docente no cenário brasileiro. Nessa pedagogia, segundo a autora, o professor é colocado na posição de herói, e a docência 
se torna uma atividade qualificada mediante uma lógica concorrencial, atingida por meio de prêmios e avaliações de larga escala.

Também, na arquitetura do dossiê, apresentamos duas resenhas: a primeira produzida por Pricila Kohls dos Santos sobre a Identidade cosmopolita global na prática educativa: da utopia a realidade, de Cezar García-Rincon de Castro; e a segunda elaborada por Simone Van Der Halen Freitas e Hildegard Susana Jung, a qual versa sobre $O$ processo de Bolonha e a globalização da educação superior: antecedentes, implementação e repercussões no quefazer dos trabalhadores da educação, de Lucídio Bianchetti.

Assim, com a parceria da Roteiro, que aprovou e investiu na proposta deste Dossiê, almejamos contribuir com reflexões acerca das inter-relações e efeitos dos organismos multilaterais nas orientações, proposições e consecução de políticas públicas da educação, a partir de diretrizes, prioridades, desafios e práticas da Educação Básica e Superior em contexto global e local, no sentido de promover um debate intenso e importante acerca das temáticas subjacentes aos textos aqui socializados.

Desejamos uma profícua leitura.

Marilene Gabriel Dalla Corte

Rosane Carneiro Sarturi

Marília Costa Morosini

Organizadoras 